\title{
Sosialisasi pemahaman kebencanaan di Kelurahan Pasie Nan Tigo, Kecamatan Koto Tangah, Kota Padang
}

\author{
Nefilinda*, Slamet Rianto, dan Jamsari \\ STKIP PGRI Sumatera Barat \\ *nefilinda@yahoo.com
}

\begin{abstract}
Abstrak. Posisi Kelurahan Pasie Nan Tigo yang berada di Pesisir Pantai Sumatera menyebabkan daerah tersebut sangat rawan terhadap bencana abrasi pantai, banjir, gempa, bahkan terancam tsunami. Oleh karena itu, maka kegiatan PKM yang dilakukan ditujukan untuk meningkatkan pemahaman dan kesiapan masyarakat di desa tersebut dalam menghadapi bencana sehingga dampak bencana yang bisa terjadi dapat dikurangi. Kegiatan dilakukan dengan metode ceramah/penyuluhan yang diikuti dengan diskusi. Hasil kegiatan memperlihatkan bahwa secara umum masyarakat cukup paham dalam menghadapi bencana. Pemahaman terhadap gejala-gejala alam khususnya terkait dampak gempa dan tsunami seperti: surutnya air laut, rumah banyak yang retak, munculnya sumber air tiba-tiba, gempa yang kuat dan berulang-ulang serta berlariannya binatang kearah darat menjadi pertanda tentang apa yang seharusnya mereka lakukan. Keputusan untuk bersedia dievakuasi dan mengungsi umumnya menunggu informasi dari pemerintah. Masyarakat juga dibekali dengan penyelamatan arsip dan dokumen keluarga berharga seperti: ijazah, sertifikat, KTP, KK, dan lain lain dengan melakukan scanning dan back up digital. Foto dan hasilnya disimpan dalam sistem cloud berupa Email atau dalam fasilitas google drive. Masyarakat juga diajarkan tentang pembuatan rambu-rambu bencana dan melakukan kesepakatan terutama dalam keluarga untuk menentukan tempat berkumpul yang aman dengan menggunakan peta jalur evakuasi terpendek atau gedung-gedung yang dapat berfungsi sebagai shelter.
\end{abstract}

Kata kunci: tsunami; mitigasi bencana; sistem cloud; google drive; sosialisasi

\begin{abstract}
The position of Pasie Nan Tigo Village on the Coast of Sumatra causes the area to be very risky to coastal abrasion, floods, earthquakes, and even by tsunamis. Therefore, the PKM activities undertaken are aimed at increasing the understanding and readiness of the community in the village in dealing with disasters so that the impact of disasters can be reduced. The activity was carried out using the lecture/counseling method followed by a discussion. The results of the activities showed that in general the community was well-informed in facing disasters. Understanding of natural phenomena especially related to the impact of the earthquake and tsunami such as: the receding of sea water, cracked houses, sudden emergence of water sources, strong and repeated earthquakes and the running of animals towards the land to be a sign of what they should do. The decision to be prepared to evacuate is generally depending on the information released by the government. The community is also equipped with saving valuable family documents such as diplomas, certificates, ID-Card, family card, etc. by doing digital scanning and backing up. Photos and results are stored in a cloud system in the form of an email or in the google drive facility. Communities are also taught about making disaster signs and making agreements especially in families to determine safe gathering places by using the shortest evacuation route map or buildings that can function as shelters.
\end{abstract}

Keywords: tsunami; disaster mitigation; cloud system; google drive; socialization

To cite this article: Nefilinda, S. Rianto, \& Jamsari. 2019. Sosialisasi pemahaman kebencanaan di Kelurahan Pasie Nan Tigo, Kecamatan Koto Tangah, Kota Padang. Unri Conference Series: Community Engagement 1: 192-201. https://doi.org/10.31258/unricsce.1.192-201

(C) 2019 Authors

Peer-review under responsibility of the organizing committee of Seminar Nasional Pemberdayaan Masyarakat 2019 


\section{PENDAHULUAN}

Indonesia adalah negara kepulauan, berdasarkan letak geografisnya dilalui oleh tiga lempeng tektonik, yaitu lempeng Eurasia, lempeng Indo-Australia, dan lempeng Samudra Pasifik. Kondisi ini menjadikan negara Indonesia sebagai "supermarket bencana" (Haryadi, 2012). Berbagai bencana telah terjadi di Indonesia, diantaranya adalah bencana geologi (gempabumi, aktivitas vulkanik) dan bencana hidrologi (banjir, tanah longsor, tsunami). Berdasarkan data dari Emergency Events Database (EM-DAT), Indonesia termasuk lima besar negara yang rawan bencana dan termasuk sepuluh besar negara dengan angka kematian tertinggi dampak bencana pada 2014 (EMDAT, 2015; Guha-sapir et al., 2015).

Sejak terjadinya gempa besar berkekuatan 7,9 Skala Richter (SR) pada tanggal 30 September 2009, masyarakat kota Padang masih dikhawatirkan akan terjadi gempa lebih besar yang dipicu tsunami. Koran Posmetro Padang 25 Februari 2012 menyajikan tentang hasil penelitian Lembaga Ilmu Pengetahuan Indonesia (LIPI) yang dikemukakan oleh pakar gempa dan tsunami Danny Hilman Natawidjaja bahwa gempa dari Sunda Megathrust berkekuatan 8,8 SR dapat memicu gelombang tsunami tinggi di seluruh wilayah pesisir pantai Sumatera Barat.

Kelurahan Pasie Nan Tigo yang berada di Pesisir Pantai Sumatera termasuk kategori daerah yang sangat rawan terhadap beberapa bencana seperti terjadinya ombak besar, yang dapat mengakibatkan sebagian rumah masyarakat terbongkar, bahkan hancur. Bencana abrasi pantai yang dialami masyarakat telah diteliti pada tahun 2015 dan dipublikasikan pada Seminar Nasional Prodi Pendidikan Ekonomi STKIP PGRI Sumatera Barat Tahun 2016. Meskipun demikian, kondisi tersebut tidak membuat masyarakat menyerah, akan tetapi mereka tetap tinggal di rumah tersebut dengan hanya menutup dinding rumah yang sudah hancur tersebut dengan seng bekas, atau pasir yang telah dimasukkan ke dalam karung dan di susun menjadi pelindung dari terjangan ombak.

Penghasilan dan tingkat ekonomi masyarakat di Pasie Nan Tigo umunya masih dibawah rata-rata dimana umumnya mereka bermata pencaharian sebagai nelayan, jika tangkapan mereka tidak habis terjual maka mereka mengolah ikan tersebut menjadi ikan kering baik sebagai ikan tawar atau ikan asin. Persoalan lainnya yang ditemui di Keluarahan tersebut adalah tidak teraturnya bangunan yang ada di Kelurahan Pasie Nan Tigo sehingga dapat menghambat evakuasi jika terjadinya bencana.

Lebih jauh, posisi Kelurahan Pasie Nan Tigo yang berada di Pesisir Pantai Barat Sumatera, maka selain potensi ancaman bencana abrasi, banjir bahkan gempa yang bisa jadi diikuti oleh tsunami menjadi suatu ancaman terhadap kehidupan masyarakat di Kelurahan tersebut. Untuk itu maka dianggap perlu untuk dilakukan sosialisasi pemahaman kebencanaan di Kelurahan Pasie Nan Tigo, Kecamatan Koto Tangah,

\section{Kota Padang.}

Beberapa permasalahan yang berhasil diidentifikasi di Kelurahan Pasie Nan Tigo antara lain: 1. Rendahnya pengetahuan dan pemahaman masyarakat dalam menghadapi bencana , 2. Rendahnya pengetahuan dan pemahaman masyarakat terkait rambu-rambu rawan bencana dan 3. Rendahnya pengetahuan dan pemahaman masyarakat terkait jalur evakuasi

Dengan dasar tersebut maka team pengusul melakukan kemitraan dengan Badan Nasional Penanggulangan Bencana Daerah (BNPBD) Kota Padang melakukan sosialisasi terkait upaya mitigasi potensi bencana yang berpeluang terjadi di kelurahan tersebut. Untuk itu, maka dilakukan beberapa kegiatan sebagai berikut: 1) Sosialisasi sikap dan tindakan yang harus dialkukan dalam menghadapi bencana, 2) Memberikan pemahaman tentang pentingnya peran rambu-rambu kebencanaan, dan 3) Membuatkan contoh jalur evakuasi bencana.

\section{METODE PENERAPAN}

Program Kemitraan Masyarakat ini dilakukan oleh dosen yang sesuai dengan bidang penelitian sebelumnya yaitu kebencanaan dan menggunakan pakar dalam melakukan diskusi untuk menghasilkan pengabdian yang bermutu sehingga masyarakat dapat melaksanakan mitigasi bencana dalam kehidupan mereka sehari-hari. Karena mereka hidup di daerah rawan bencana, berupa abrasi pantai, banjir dan gempa. Team pengusul pengabdian juga melakukan evaluasi terhadap kegiatan berupa evaluasi proses, evaluasi akhir dan evaluasi tindak lanjut. Indikator pencapaian tujuan dan tolak ukur yang digunakan untuk menjustifikasi tingkat keberhasilan kegiatan dapat dilihat pada kerangka berfikir pada Gambar 1.

Kegiatan PKM yang dilakukan oleh pengusul merupakan kewajiban dalam melaksanakan Tri Dharma Perguruan Tinggi. Team pengusul terdiri dari Dosen STKIP PGRI Sumatera Barat dan Dosen Unand. Dalam pelaksanaannya PKM dibantu oleh tiga orang enumetaror dan team pembantu penelitian dalam pengambilan 
data primer dan sekunder terkait di lokasi kegiatan. Pengusul pengabdian juga bekerjasama dengan pemerintah (BNPBD) Kota Padang.

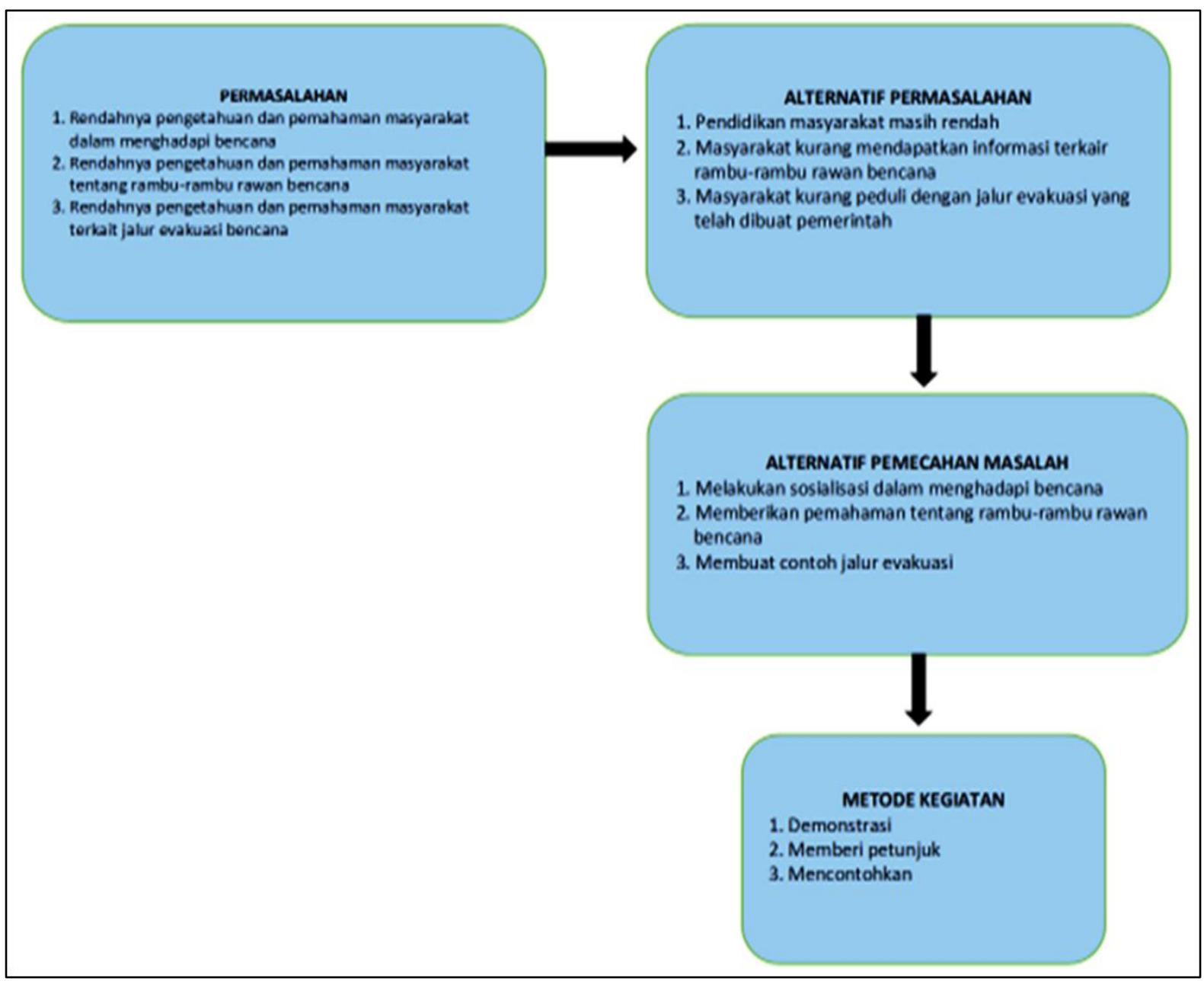

Gambar 2. Kerangka Berfikir

\section{HASIL DAN KETERCAPAIAN SASARAN}

Pengabdian pada masyarakat tentang sosialisasi pemahaman kebencanaan di Kelurahan Pasie Nan Tigo, Kecamatan Koto Tangah, Kota Padang, telah dilaksanakan dengan prosentase $70 \%$ yang dimulai dari tanggal 10 Februari 2019 sampai tanggal 30 Juni 2019. Kegiatan-kegiatan yang telah dilaksanakan oleh team PKM yaitu:

1. Pengurusan administrasi berupa surat izin pengabdian, mulai dari Dinas Penanaman Modal dan Pelayanan Satu Pintu, Kesbangpol Kota Padang, Kantor Camat Koto Tangah, Kantor Lurah Pasie Nan Tigo.

2. Kerjasama dengan BPBD Kota Padang, untuk melaksanakan PKM dengan saling mendukung agar meningkat pemahaman masyarakat tentang kebencanaan.

3. Kerjasama dengan Kelompok Siaga Bencana (KSB) yang ada di Kelurahan Pasie Nan Tigo (Ibu Dewi dan Ibu Reni), koordinasi dengan Bapak Lurah (Bapak Taslim, S.Sos), Bapak RW, Bapak RT setempat.

4. Setelah terjalin kerjasama yang baik, maka team dapat membicarakan tindak lanjut kegiatan pengabdian pada masyarakat di Kelurahan Pasie Nan Tigo. Untuk menentukan hari dan tanggal kegiatan PKM ini maka Bapak Taslim memberikan permintaan kepada pihak RT dan RW untuk membantu PKM yang akan di laksakana di lingkungan mereka. Oleh sebab itu team meminta persetujuan sekaligus untuk meminta izin kepada Bapak RT (Bapak Asril) agar dapat melaksanakan PKM. Dari pertemuan tersebut diperoleh izin dan mereka menyambut baik kegitan PKM yang akan dilaksanakan. 

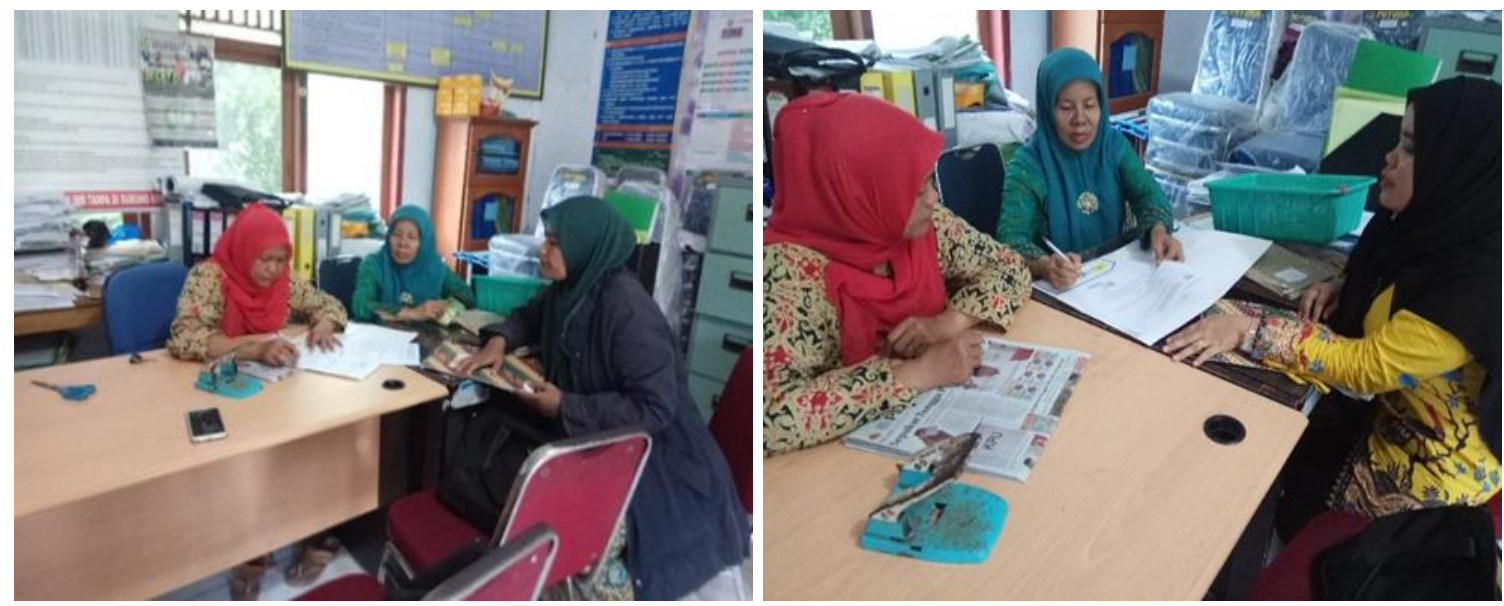

Gambar 2. Pengurusan surat izin PKM di Kelurahan Pasie Nan Tigo
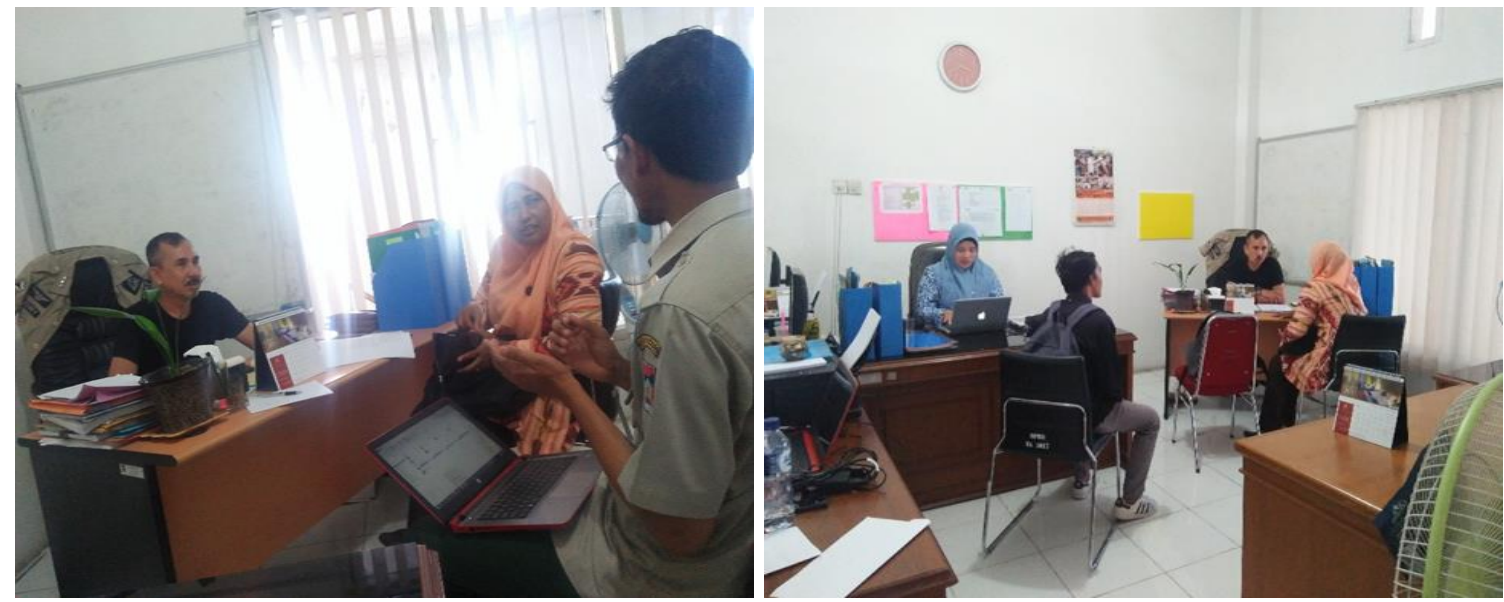

Gambar 3. Melakukan kerjasama dengan BPBD Kota Padang yang berkantor di By Pass dengan Bapak Hendri selaku Kepala Bidang Kebencanaan dan Bapak Resko selaku team pelaksana dalam kegiatan kebencanaan
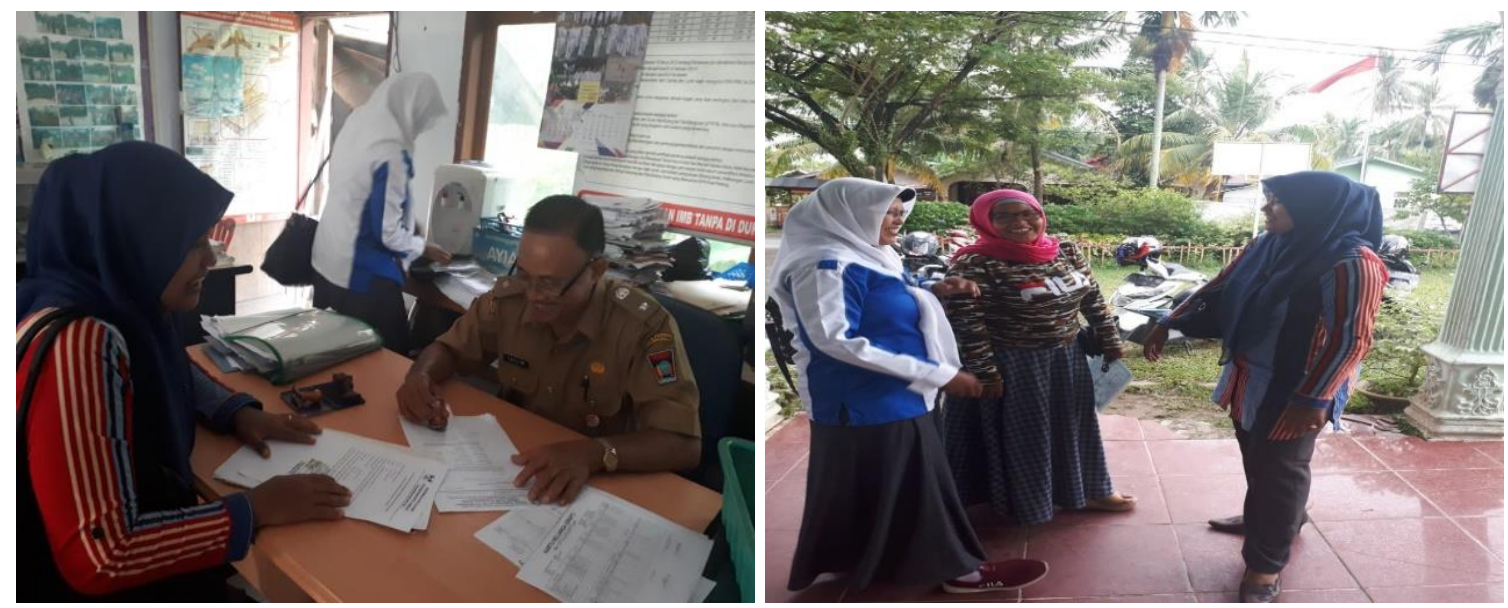

Gambar 4. Bekerjasama dengan pihak KSB Kelurahan Pasie Nan Tigo yaitu: Ibu Dewi dan Ibu Reni. Dilanjutkan dengan kerjasama dengan Bapak Taslim. S.Sos selaku Lurah di Pasie Nan Tigo 


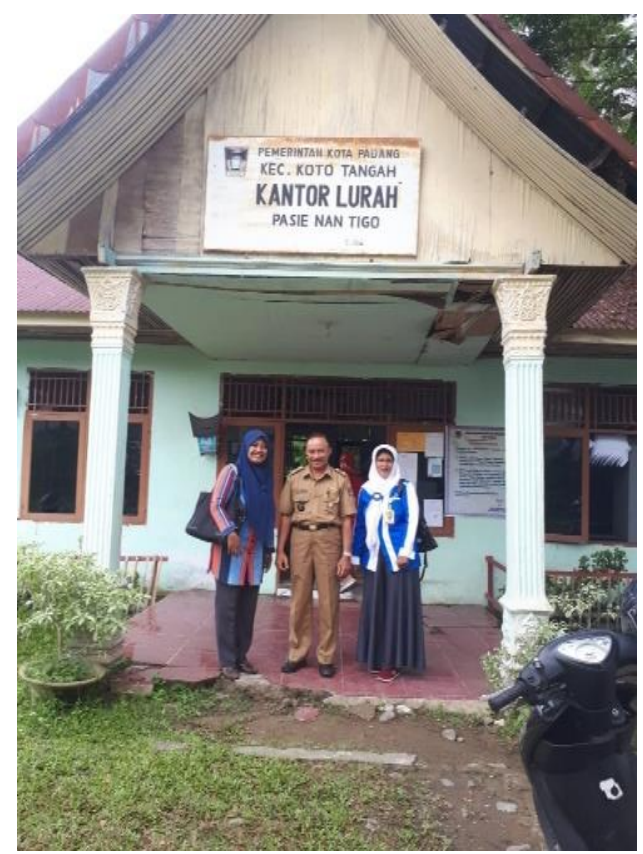

Gambar 5. Menjalin kerjasama dengan Bapak Taslim, S.Sos selaku Lurah di Kelurahan Pasie Nan Tigo

\section{Pelaksanakan PKM}

Team mempersiapkan peralatan (laptop dan infokus) anggota, mahasiswa yang ikut, masyarakat yang berminat, tempat, dan lainnya. Telah ada kesepakatan untuk melaksanakan PKM yaitu di hari sabtu tanggal 18 Mai 2019. Dihadiri oleh 22 orang yang terdiri dari Ketua berserta anggota PKM, mahasiswa, dan masyarakat Kelurahan Pasie Nan Tigo. Acara dimulai dari Jam 13.00 sampai 17.30 WIB.
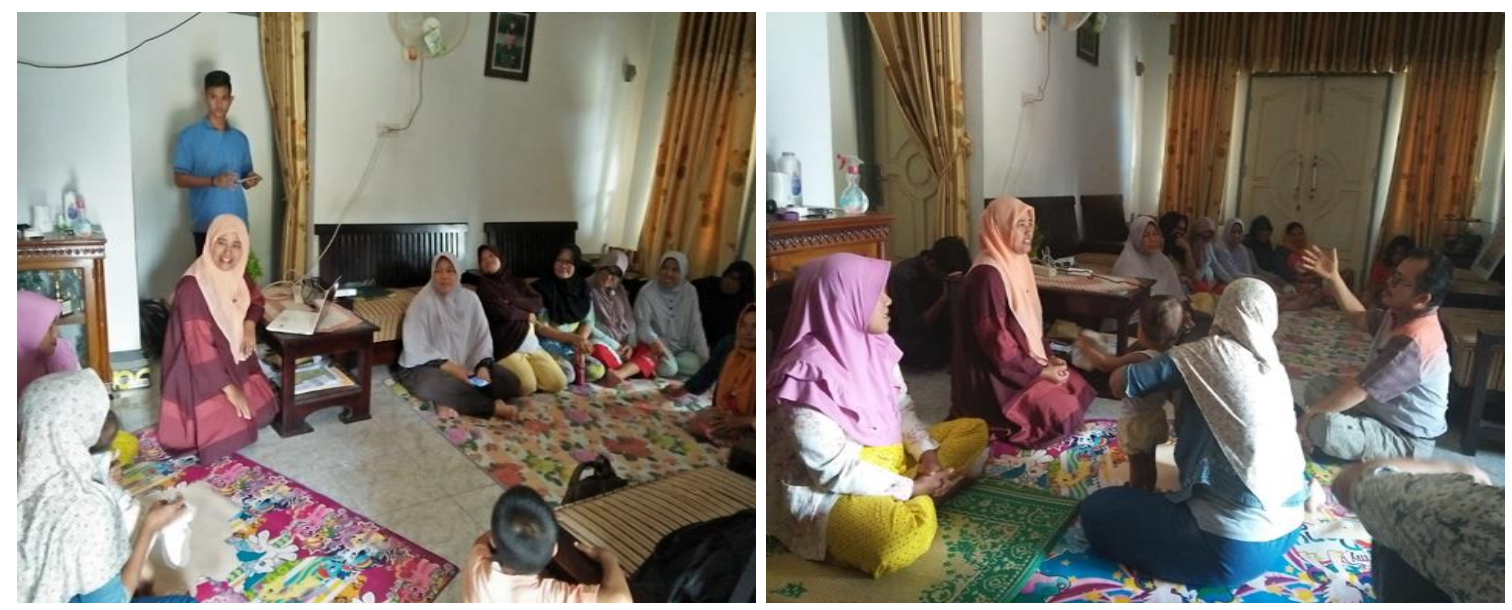

Gambar 6. Acara pembukaan PKM disampaikan oleh Ketua yaitu Ibu Dr. Nefilinda, SE, M.Si dan Penyampaian materi oleh Bapak Slamet Rianto, M.Pd

PKM dilaksanakan di Komplek Pamela II, di posko keamanan milik masyarakat komplek. Dilaksanakan persiapan sosialisasi oleh ketua dan anggota dan dibantu oleh 5 orang mahasiswa (Bayu Anggara, Jandarles Saleku, Rudi Putra, Fendar Ristian dan Dopler). Mahasiswa ini adalah perwakilan dari Program Studi Pendidikan Geografi yang ingin mengetahui bagaimana riilnya pelaksanaan PKM di masyarakat. Persiapan berupa pemasangan laptop, infokus serta tikar untuk tempat duduk warga yang akan mengikuti sosialisasi. Kekompakan dan antusian masyarakat terlihat ketika akan di adakan acara PKM, sebagaian ibu-ibu sudah membawa tikar dari rumah masing-masing yang akan di gunakan untuk alas duduk. Walaupun ada beberapa warga yang membawa anak bayinya untuk tetap mengikuti acara PKM, dengan alasan ingin mengetahui cara untuk menghindar dari bencana. Setelah selesai dan di cobakan, ternyata power point dan vodeo yang di tembak ke dinding tidak Nampak sama sekali, karena posko keamanan ini tidak ada dinding dan telalu terang. Jadi kami meminta kepada salah satu warga untuk dapat menggunakan rumahnya untuk tempat sosialisasi. 
Rumah di depan posko milik ibu Jun, bersedia untuk di gunakan, Sehingga akhirnya kami memulai persiapan kembali untuk acara.

Acara di buka oleh ketua PKM Dr. Nefilinda, SE, M,Si, menyampaikan maksud dan tujuan di akukannya PKM di daerah ini. Alhamdulillah masyarakat menyambut baik maksud dan tujuan tersebut. Selanjutnya kami putarkan video tentang kejadian gempa, tsunami dan beberapa education yang dapat di peroleh dari video yang ditayangkan. Selanjutnya materi yang disampaikan oleh Bapak Slamet Rianto, M.Pd terkait "Sosialisasi dalam menghadapi bencana dan membuat contoh jalur evakuasi".

Ada beberapa inti dari materi yang disampaikan oleh Team Pengabdian yaitu:

a. Mempersiapkan diri sebelum terjadinya bencana, yaitu mengaarsipkan semua dokumen penting milik semua anggota keluarga, contohnya KTP, KK, Akta kelahiran, Ijazah, sertivikat, dan lain sebagainya. Dengan cara menscan atau memfoto dokumen tersebut dan menyimpannya dalam bentuk file di CD atau Flashdisk, bahkan lebih mudah dapat di simpan di email atau Google drive. Jika bencana gempa dan diikuti oleh tsunami masyarakt sudah dapat mengamankan dokumen keluarga dengan baik.

b. Membuat kesepakatan dengan anggota keluarga, jika terjadi bencana gempa. banjir atau tsunami maka ada tempat tujuan yang keluarga sepakati untuk berkumpul. Contohnya di Gedung UMSB. Sehingga dapat mempermudah dalam menentukan jalur evakuasi keluarga. Hal ini penting di sepakati, karena keluarga mempunyai jalan tersendiri untuk menempuh ke lokasi yang disepakati. Contoh ada jalan kecil yang aman dari bencana tersebut dan anggota keluarga tahu. Itu akan memendekkan waktu untuk sampai ke tempat yang aman dan telah di sepakati bersama dengan anggota keluarga. Sebaiknya jalur evakuasi ini tidak menggunakan jalan pada umumnya, karena kalau menggunakan jalur atau jalan umum maka pasti macet dan berdesakan. Jangan menggunakan kendaraan bermotor agar maksimal menyelamatkan diri.

c. Masyarakat harus mengenali situasi alam, jika ada tanda-tanda seperti air surut tidak seperti biasanya, banyak binatang di sekitar pantai gelisah atau berlarian kearah daratan maka masyarakat harus waspada, itu merupakan salah satu tanda-tanda akan terjadi gelombang besar bahkan tsunami.

d. Masyarakat harus tenang dalam menghadapi bencana, dengan hati yang tenang maka masyarakat dapat berpikir yang baik, mana jalan yang harus di lalui dengan jarak yang dekat dan waktu yang sedikit dapat menuju ke tempat yang tinggi dan telah di sepakati oleh anggota keluarga, agar terhindar dari bencana. Sesuai dengan UU No. 24 tahun 2007 tentang penanggulangan bencana yang menyatakan bahwa "bencana didefinisikan sebagai peristiwa atau rangkaian peristiwa yang mengancam dan mengganggu kehidupan dan penghidupan masyarakat yang disebabkan, baik oleh faktor alam dan/atau faktor non alam maupun faktor manusia sehingga mengakibatkan timbulnya korban jiwa manusia, kerusakan lingkungan, kerugian harta benda, dan dampak psikologis". Artinya masyarakat harus tenang dan berfikir mencari jalur evakuasi yang terdekat dan aman.

e. Sebenarnya ada beberapa gedung tinggi yang berlantai 2 bahkan lantai 3 yang dapat digunakan sebagai selter alternative, walaupun tidak berfungsi sebagai selter di sekitar Kelurahan Pasie Nan Tigo, contohnya Gedung Rasunawa, memiliki jenjang di dalam gedung dan tidak mempunyai ruangan lepas di lantai paling atas. Beberapa rumah penduduk yang berlantai 2 dan lantai 3 juga dapat digunakan.

Setelah penyampaian materi. Maka di adakan tanya jawab terkait sosialisasi yang telah diberikan. Yang mengajukan pertanyaan:

a. Ibu Dewi (anggota KSB): bagaimana cara masyarakat menyelamatkan diri jika tidak terlihat gejala alam, tetapi muncul saja tsunami seperti di Jawa Barat?

Jawaban team PKM: perbanyak tawakal dan pasrah kepada Alloh tapi harus juga berusaha untuk menghindar dari bencana dengan cara mencari jalan terdekat menuju lokasi aman seperti gedung tinggi yang ada di sekitar mereka, seperti RASUNAWA dan UMSB.

b. Ibu Jun: apakah tidak ada alarm yang di pasang di sekitar kami, agar kami bisa menyelamatkan diri ?

Jawaban team PKM: alaram sebenarnya sudah di pasang di beberapa tempat, tetapi mungkin ada yang penggunaannya tidak maksimal, seperti berbunyi akan tetapi tidak terjadi apa-apa. Atau tidak berbunyi sama sekali karena baterai alaram tersebut dicuri oleh orang yang tidak bertanggung jawab. Ini merupakan kendala bagi masyarakat yang kurang peduli terhadap pemasangan alaram, pada hal itu sangat berguna untuk kepentingan masyarakat. 
c. Ibu Pit memberikan saran: sebaiknya sosialisasi ini sering diberikan ke masyarakat kami karena kami berada di tepi pantai yang rawan terhadap bencana.

Jawab team PKM: rencana memang kami akan melakukan beberapa kali sosialisasi, simulasi, pemahaman, mencontohkan, Pendidikan dan pelatihan kepada masyarakat di Kelurahan Pasie Nan Tigo ini, agar masyarakat dapat terhindar atau menghindar dari bencana, sehingga dapat meminimalisir jatuhnya korban.
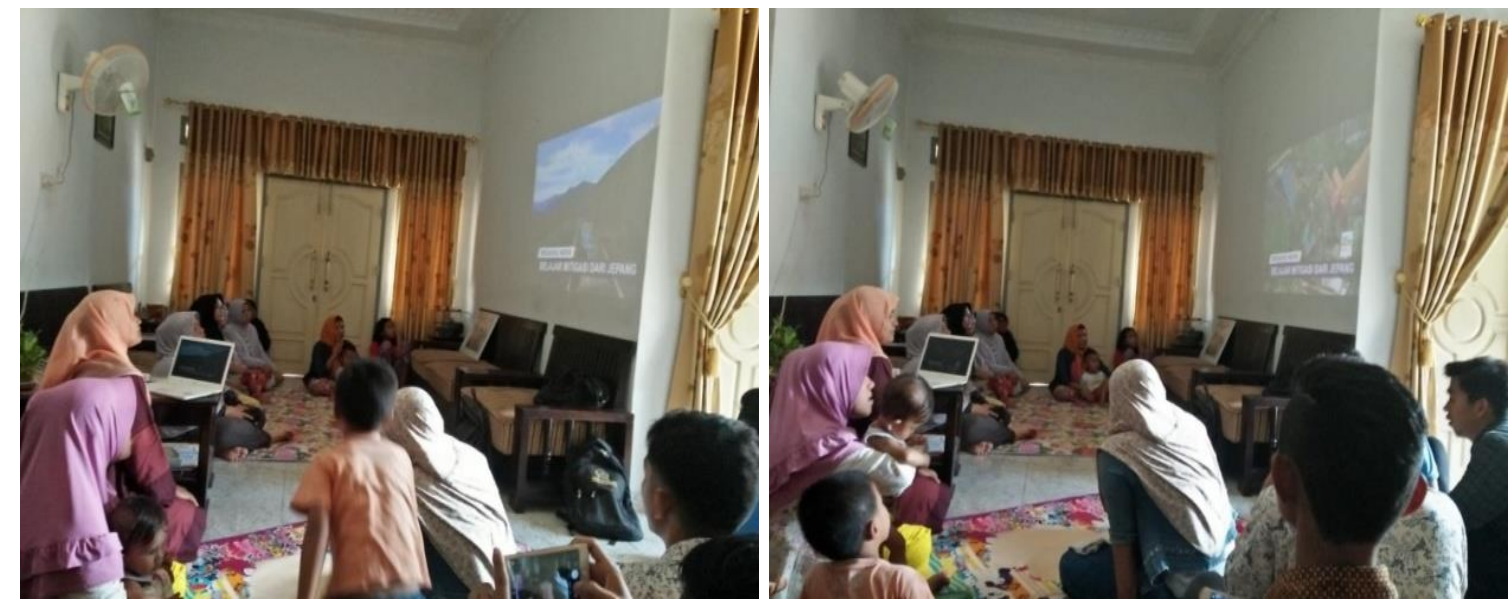

Gambar 7. Ketua dan Anggota PKM menjawab beberapa pertanyaan yang diajukan oleh masyarakat dengan menggunakan data atau contoh kasus yang ada untuk meminimalisir dampak bencana

Setelah selesai memberikan sosialisasi masyarakat berharap agar mereka sering diberi ilmu pengetahuan, pemahaman tentang bencana agar masyarakat bisa mempersiapkan diri baik secara fisik dan mental. Oleh sebab itu perlu adanya materi tentang tindakan yang harus dilakukan sebelum bencana terjadi. Setelah itu dilanjutkan dengan materi tentang tindakan yang harus dilakukan saat bencana dan materi tentang tindakan pasca bencana, dalam PKM yang dilakukan oleh Bagus Wibowo, dkk (2017). Sedangkan menurut Trina Ahdiati (2017), Desa Widarapayung Wetan merupakan kawasan yang kaya akan potensi ekoturisme namun sangat rawan terhadap bencana. Oleh karena itu, dibutuhkan upaya untuk mengantisipasinya dengan melakukan pemberdayaan masyarakat untuk pengembangan ekoturisme melalui metode pelatihan dan pendampingan penguasaan jejaring media sosial sebagai bekal bagi masyarakat untuk lebih mengembangkan kreativitas dan promosi ekoturisme sekaligus mengurangi risiko bencana.

Pertemuan berikutnya dihadiri oleh masyarakat, mahasiswa dan pelaksana PKM yang diadakan di kedai Ibu Yani, Ibu Bet dan Ibu Wati yang terletak di pinggiran pantai. Ibu Yani bermata pencaharian sebagai penyewa pondok, menyewa tikat, berjualan makanan (mie rebus, kue kering, dll) dan minuman (air kelapa muda, minuman botol, dll) di pinggiran pantai yang dapat di gunakan oleh wisatawan untuk tempat duduk ketika berekseasi ke pinggiran pantai Pasie Nan Tigo. Hal ini dapat menunjang pendapatan keluarganya.Akan tetapi lokasi mereka mencari nafkah ini merupakan kawasan rawan bencana, oleh sebab itu perlu dilakukan sosialisasi tentang rambu-rambu rawan bencana, yang bertujuan agar mereka selalu siap siaga jika bencana itu dating secara tiba-tiba. Sosialisasi kali ini terkait dengan rambu-rambu rawan bencana.

Dari 11 gambar rambu-rambu rawan bencana, masyarakat pernah melihat akan tetapi belum paham maknanya. Oleh sebab itu pelaksana PKM memberikan pengertian dan pemanahan tentang gambar tersebut, yaitu:

a. Peringatan telah berada pada kawasan rawan bencana gempa bumi

b. Peringatan telah berada pada kawasan rawan bencana tsunami

c. Peringatan telah berada pada kawasan rawan bencana banjir

d. Peringatan zona bahaya tsunami

e. Daerah evakuasi tsunami

f. Petunjuk tempat pengungsian

g. Petunjuk tempat kumpul sementara

h. Petunjuk lokasi posko

i. Gedung evaluasi tsunami

j. Petunjuk arah jalur evakuasi

k. Petunjuk tempat pengungsian 
Dari 11 gambar tersebut diberikan sosialisasi untuk menambah pengetahuan dan pemahaman tentang rambu-rambu rawan bencana, sehingga masyarakat dapat mewaspadai diri dan anggota keluarga dari bencana gempa, banjir dan bahkan tsunami yang sewaktu-waktu datang.
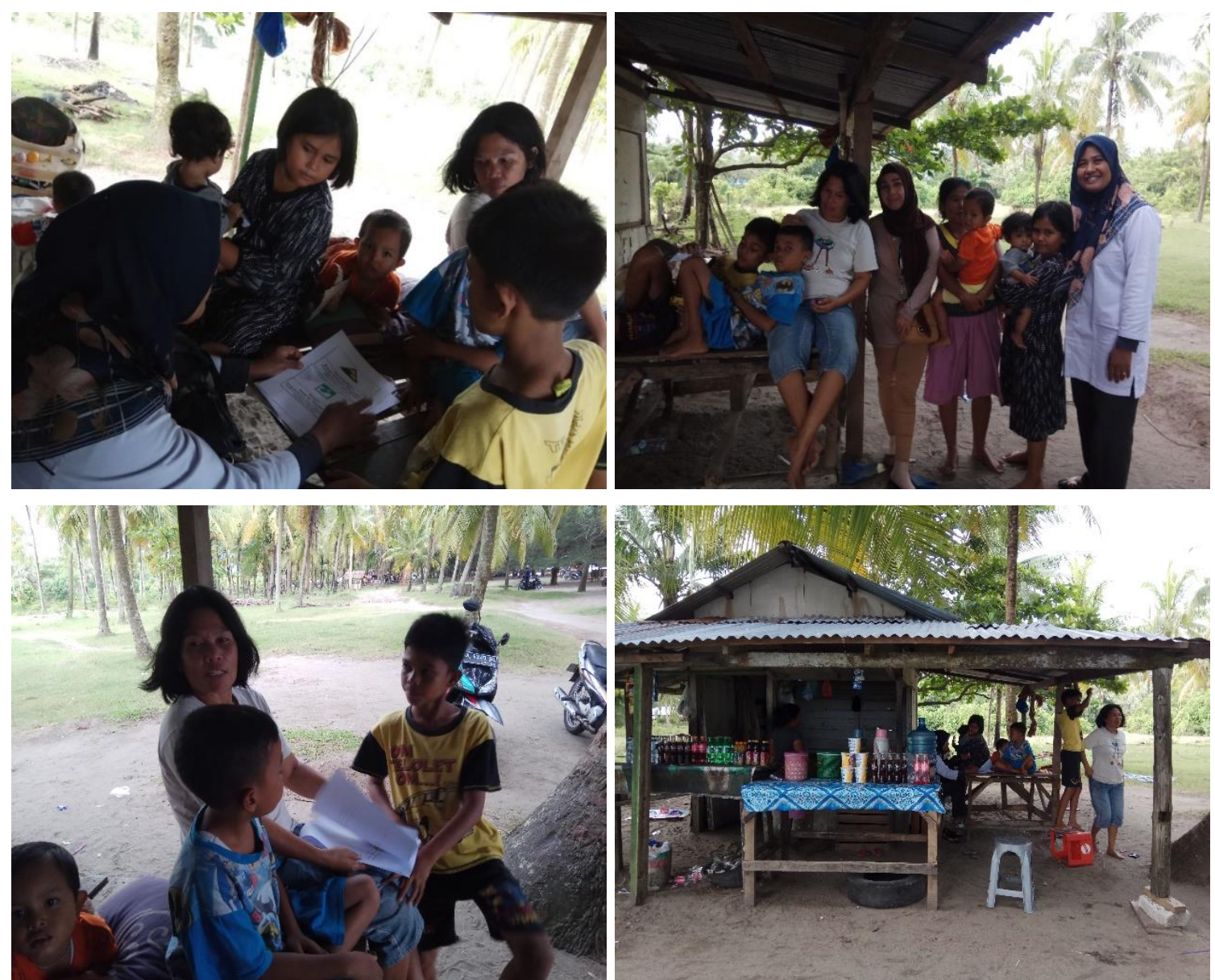

Gambar 8. Sosisalisasi tentang rambu-rambu rawan bencana

Bapak Taslim, S.Sos dan Bapak Asril selaku RW di sana menyampaikan rasa senangnya karena sudah memberikan pencerahan kepada masyarakatnya terkait kebencanaan. Sesuai dengan pendapat Poli Hanny (2019), Dengan memiliki pengetahuan dan ketrampilan bidang kebencanaan dapat memberikan rasa aman,tentram, dan nyaman bermukim pada lokasi permukiman yang sudah ditinggali selama ini.

Kondisi yang cukup mengkhawatirkan adalah tingkat kesiapsiagaan seseorang bersifat dinamis, maksudnya dapat menurun setiap saat seiring berjalannya waktu (Hidayati et al., 2006). Oleh sebab itu perlunya dilakukan pengabdian kepada masyarakat, agar masyarakat selalu waspada terhadap bencana gempa, banjir dan tsunami yang selalu mengintai mereka.

\section{KESIMPULAN}

Beberapa kesimpulan yang dapat di tarik dari pelaksanaan kegiatan PKM ini adalah:

1. Pengetahuan dan pemahaman masyarakat yang masih rendah dalam menghadapi bencana dapat diminimalisir dengan melakukan sosialisasi tentang kesiapan masyarakat dalam menghadapinya.

2. Pengetahuan dan pemahaman masyarakat terkait rambu-rambu rawan bencana yang masih rendah, dapat ditingkatkan dengan cara memberikan pemahaman kepada masyarakat melalui 11 gambar rambu-rambu rawan bencana.

3. Pengetahuan dan pemahaman masyarakat terkait jalur evakuasi yang masih rendah, dapat diperbaiki dengan memberikan contoh jalur evakuasi seperti yang telah mereka sepakati dalam anggota keluarga. 

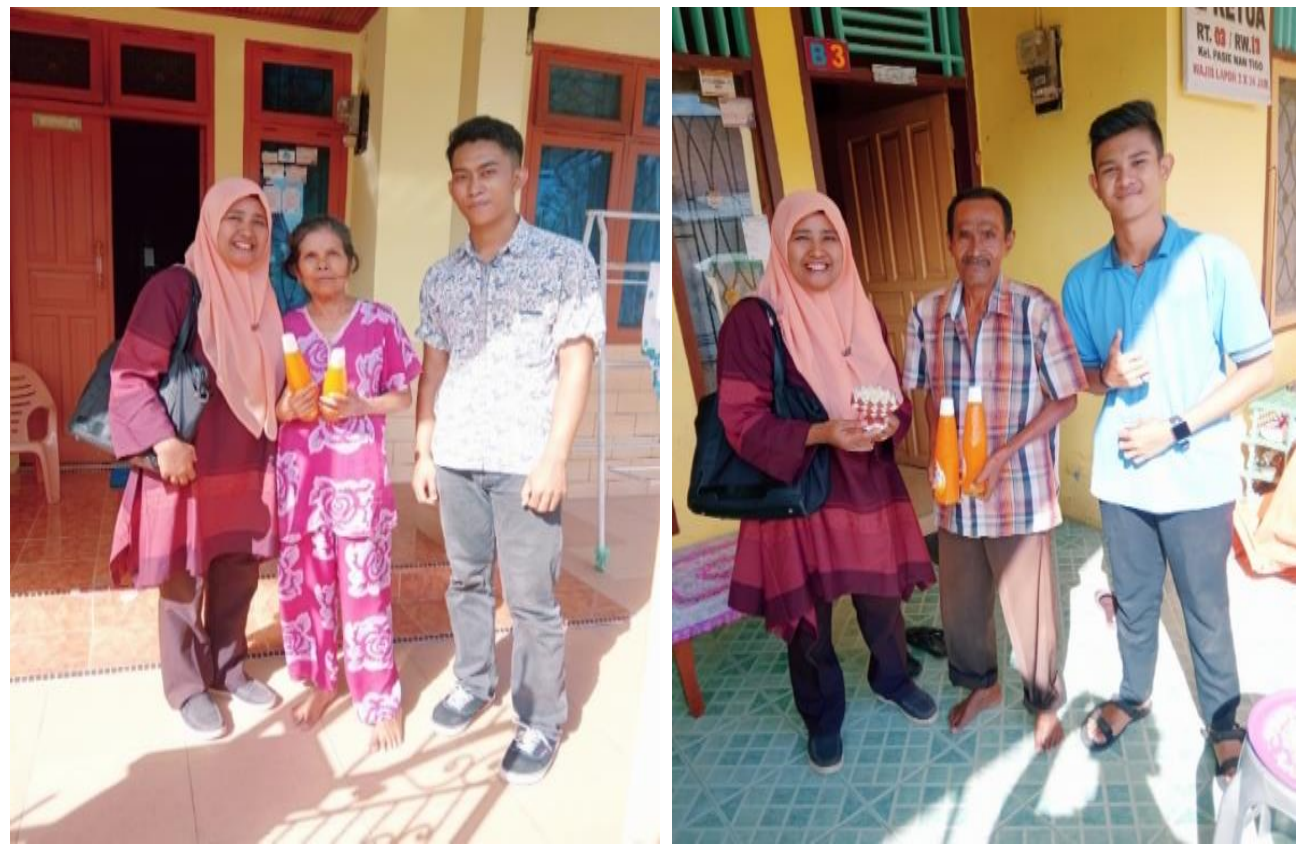

Gambar 9. Ucapan terima kasih dari perwakilan Bapak Lurah dan Bapak RT setempat.

\section{UCAPAN TERIMA KASIH}

Ucapan terima kasih disampaikan kepada:

1. Ketua STKIP PGRI Sumatera Barat yaitu Ibu Dr. Zusmelia, M.Si, beserta Wakil-wakilnya yang telah memberi kesempatan kepada Team PKM untuk melaksanakan PKM.

2. Kepala UP3M yaitu Ibu Villia Anggraini, M.Pd, yang telah membantu terlaksananya PKM.

3. Pimpinan Prodi Pendidikan Geografi STKIP PGRI Sumatera Barat, yang telah mendukung dan mensupport terlaksananya PKM.

4. Pimpinan Fakultas Pertanian UNAND, yang telah memberi izin kepada anggota PKM untuk melaksanakannya dengan baik.

5. Bapak Lurah dan Bapak RT yang telah memberi izin dan mensupport pelaksanaan PKM di daerah yang mereka pimpin.

6. DRPM selaku penyandang dana untuk pelaksanaan PKM 2019.

7. Beberapa orang asisten lapangan, yang telah mensukseskan kegiatan pelaksanaan PKM.

8. Team yang telah bekerjasama dalam melaksanakan PKM dengan kekompakan dan kesungguhan hati.

\section{DAFTAR PUSTAKA}

EMDAT, UNISDR. 2015. Top Ten Number of Reported Disasters by Country. http://www.unisdr.org/files/47804_2015_disastertrendsinfographic.pdf\&usg

Hanny, P., Papia, J. C. Franklin, dan R. M. S. Lakat. 2019. Pemberdayaan Masyarakat dalam Kesiap Siagaan Mengantisipasi Ancaman Bencana Alam di Desa Kali dan Kali Selatan Minahasa. MEDIA MATRASAIN. 16(1).

Haryadi, W. 2012. Gempa Tektonik di Pulau Sumbawa dan Dampaknya Terhadap Bangunan Sipil(Suatu Kajian Geologis). 6:13.

Hidayati, D., et al. 2006. Kajian Kesiapsiagaan Masyarakat dalam Mengantisipasi Bencana Gempa Bumi dan Tsunami di Indonesia. Indonesia: LIPI-UNESCO/ISDR.

MacDonald, C. 2012. Understanding Participatory Action Research: A Qualitative Research Methodology Option. The Canadian Journal of Action Research 13(2): 34-50.

Posmetro Padang. 2012. Jangan tunggu air laut surut: Gempa 8,8 SR mengintai. Sabtu, 25 Februari 2012.

Triana Ahdiati, M. Soebiantoro dan Solahuddin K. 2017. Penguatan Masyarakat Rawan Bencana Melalui Penguasaan Media Sosial untuk Pengembangan Ekoturisme di Desa Widarapayung Wetan Kabupaten Cilacap. Prosiding 
Seminar Nasional dan Call for Papers "Pengembangan Sumber Daya Perdesaan dan Kearifan Lokal Berkelanjutan VII"17-18November 2017. Purwokerto.

Undang-undang RI No. 24 tahun 2007 tentang Penanggulangan Bencana.

Wibowo, B., dkk. 2017. Disaster Mitigation Pop-Up Book sebagai Media Pembelajaran Mitigasi Bencana Berbasis Kearifan Lokal bagi Siswa Sekolah Dasar. Geomedia 15(1). 